which affects nearly 500,000 people a year and is the fifth most deadly cancer in women.

The physics prize went to Japan's Makoto Kobayashi of the High Energy Accelerator Research Organization (KEK) in Tsukuba and Toshihide Maskawa of Yukawa Institute for Theoretical Physics at Kyoto University for discovering the origin of the 'broken symmetry' that contributed to a preponderance of matter over antimatter in the Universe. They share the prize with Yoichiro Nambu of the Enrico Fermi Institute at the University of Chicago in Illinois, who discovered the mechanism by which spontaneous broken symmetry occurs in particle physics.

Symmetry breaking describes how symmetrical systems can suddenly show a preference for one direction over another. As a simple example, imagine balancing a pencil on its tip. Viewed from the top, the balanced pencil appears symmetrical, but after a time it will fall and point in a single direction.

This concept applies to many physical systems, including superconductors, but it was Nambu who extended the theory to fundamental particles, according to John Ellis, a theorist at CERN, Europe's particle-physics laboratory near Geneva, Switzerland. Physicists now think that symmetry breaking is responsible for the creation of the Higgs boson, the particle that is believed to endow all other particles with mass,
Still, Walport says that the Wellcome Trust is not anticipating any need to alter its spending. Like most charities, it gives only a small fraction of its endowment to research each year - around $£ 500$ million in 2007. That relatively low rate of spending combined with careful management ahead should allow the charity to continue normal operations. "We are weathering the storm as well as can be expected," Walport says.

Cold Spring Harbor's US\$300 million endowment is also down, says Stillman, by an estimated $5 \%$ as of 31 July. And the laboratory, which supports a broad range of basic biological science, depends on additional philanthropic and corporate support to fund its roughly $\$ 120$-million operating budget. Stillman says that the money often comes either directly from Wall Street firms or from wealthy investors. The latest fundraising efforts are on track, he says. But "obviously the situation will affect our income down the road".

Rooney says that corporations may be the first to cut back on their giving. "Corporate donations are largely driven by changes in profitability," he says.

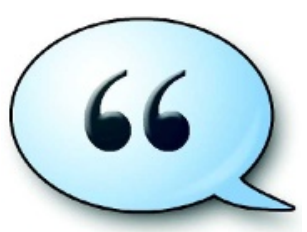

HAVE YOUR SAY Comment on any of our news stories, online. www.nature.com/news and which is a target of CERN's Large Hadron Collider.

Kobayashi and Maskawa showed how violation of symmetry could create more matter than antimatter in the Universe - a long-standing problem in particle physics. In the early 1970s, the pair showed that the interactions of quarks via a fundamental force, called 'the weak force', could cause 'CP-violation', a phenomenon by which some particles decay in a different way from their anti-matter counterparts.

"They wrote down this huge expression whose physical interpretation is the violation of symmetry between matter and antimatter," says Ken Peach, a physicist at the University of Oxford, UK. The equations also predicted a third family of quarks (the particles that make up protons and neutrons in an atom's nucleus).

The idea of a thirds family seemed "farfetched" at the time, says Ellis, but Kobayashi and Maskawa's work has since been verified by two high-energy experiments. The Belle experiment at KEK and the BaBar experiment at the Stanford Linear Accelerator Center in California both measured the decay of particles made of bottom quarks. The physicists' predictions were borne out to a high degree of accuracy. Alison Abbott and Geoff Brumfiel

To read coverage of the Nobel Prize in Chemistry, which had not been announced as Nature went to press, visit www.nature.com.

\section{Kavli invests}

\section{in institutes}

US philanthropist Fred Kavli has embarked on a second round of grants of up to $\$ 5$ million to each of the 15 research institutes that were established in his name. The grants, Kavli told Nature, are conditional on the institutes finding gifts from other donors so that they can establish endowments of $\$ 20$ million.

Kavli, who made his \$600-million fortune through real estate and selling his company - which had become a leader in supplying aeronautic and automotive sensors - says that the second round could take five years or more. "Right now the market hasn't been very kind to us," he says. "We are hedging a little on this."

Seven years ago, when Kavli established the first of the institutes, at the University of California at Santa Barbara, he developed what became a relatively strict formula:

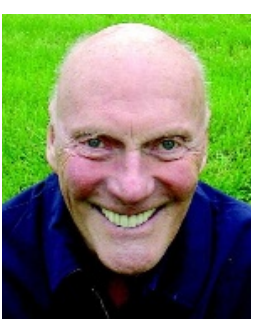

Fred Kavli is hoping to support 20 institutes. on average each university got $\$ 7.5$ million, to be supplemented and used however - for a building, for operating expenses, or for endowed professorships. Kavli got the name. for charities that depend entirely on annual donations to fund research. "Donors may raise their bar," warns Deborah Brooks, cofounder of the Michael J. Fox Foundation for Parkinson's Research in New York. Brooks says she thinks that wealthy individual donors will probably continue to give large sums but "their first instinct is to give to fewer people".

Stillman says he expects that Wall Street's woes will have a "significant" effect on research universities and charities across the state. Indeed, one important source of funding has dried up for good. Lehman Brothers, which filed for bankruptcy last month, donated roughly $\$ 7$ million to biomedical research in 2007. Most of the money went to hospitals and research centres in the New York area, with the largest amount, $\$ 6$ million, going to Weill Cornell Medical College's Lehman Brothers Lung Cancer Research Center. A spokesperson for the school declined to comment on the centre's future, saying only that it was "grateful for the many years of support by Lehman Brothers". Geoff Brumfiel
John Carlstrom, director of the Kavli
Institute for Cosmological Physics at the University of Chicago in Illinois, says that his university was not the only one that thought the gift was relatively small to be exchanged for the naming rights to an entire institute. But many assumed, apparently correctly, that more money would be coming later.

The first of the second round of gifts was completed in May to the Kavli Institute for Particle Astrophysics \& Cosmology to Stanford University in Menlo Park, California. A deal with the University of California at Santa Barbara is in the works as fundraisers find matching gifts.

Kavli, 81, says that he views the institutes, which specialize in nanoscience, neuroscience, astrophysics and theoretical physics, as his legacy - and as more important than the three $\$ 1$ million eponymous prizes that were awarded for the first time this year. But he says that he is not done yet; he eventually envisions 20 institutes. Eric Hand 